\title{
The Promotion of Reading Behavior in Early Childhood in a Densely Populated Area of Bangkok
}

\author{
Parichard Sa-nguanlak $^{1} \&$ Piyathida Khajornchaikul $^{1}$ \\ ${ }^{1}$ Faculty of Public Health, Mahidol University, Bangkok, Thailand \\ Correspondence: Piyathida Khajornchaikul, Faculty of Public Health, Mahidol University, Bangkok, Thailand. \\ E-mail: piyatida.kha@mahidol.ac.th
}

Received: December 23, 2021

Accepted: January 26, 2022

Online Published: Janaury 31, 2022

doi:10.5539/ass.v18n2p11

URL: https://doi.org/10.5539/ass.v18n2p11

\begin{abstract}
This research aimed to study the factors associated with the promotion of reading behavior in early childhood, in a densely populated area of metropolitan Bangkok, Thailand. A self-administered questionnaire was used to collect data from 228 families with children aged 3-6 years old. It was analyzed by obtaining the correlations and variables influencing reading behavior promotion. The research findings revealed that factors associated with promotion of reading behavior in early childhood with statistical significance $(p<0.05)$ were age, education, family income, and community environment. It is therefore suggested to promote reading behavior in early childhood by building a network or organization within community environments; supporting convenience, proximity, and opportunity for local families to access information on reading.
\end{abstract}

Keywords: reading, behavior, early childhood, family, language

\section{Introduction}

Reading is a fundamental resource for: building oral language skills, creativity, acquisition of new knowledge, obtaining information through the media, books, television, and the computer; and it is an effective means of systematic development of language and personality (Chettri \& Rout, 2013; Kourkouta et al., 2018).

Statistics from the UNESCO Institute for Statistics (UIS) (UNESCO Institute for Statistics, 2017) estimate that $56 \%$ of children in the world are unable to read proficiently until they complete primary education. Sub-Saharan Africa reports that $88 \%$ of children and adolescents are unable to read proficiently until they complete primary and lower secondary education too. The United Kingdom, in the year 2014, showed that one in every five children could not read at a satisfactory level until age 11 (Department for Education, 2015). In addition, the National Statistics Office (NSO) of Thailand, (2020) reported that in 2015 and 2018 the reading rates of young children, aged less than 6 years old, were $60.2 \%$ and $61.2 \%$, respectively. Rates for girls were $60.9 \%$ and $63.0 \%$, respectively, and for boys $59.5 \%$ for both years. For young children in Bangkok the reading rate was $76.2 \%$ whereas in the Northeast it was only 55.9\%. However, there were no statistics for young children in densely populated areas.

Noam Chomsky's theory of language emphasizes early brain development, biological disposition, and cognitive function. He believes that the right environment is necessary for building language skills and emphasizes stimulating the innate ability of children; and that children are not able to learn anything as complicated as human language. They cannot learn language skills unless they already have language wiring for grammatical structures in the brain. These conditions are called the Universal Grammar. Grammatical structure activation is triggered by perceiving spoken language. He also believed that children rapidly acquire language that they commonly hear (The NSW Office of Child Care, 2006). Then Vygotsky, in Sociocultural Theory, believed that adult and peer interaction encouraged children to learn language. That young children learned beliefs, values, and customs as well as language in their cultural context while interacting with other people, especially family and caregivers. He believed that language skills were essential tools for thinking and played crucial roles in cognitive development (Levine \& Munsch, 2018).

Family is the first teacher and social institution that influences behavioral development of children (Ceka, \& Murati, 2016). Research shows that if a 4-year-old child is read-aloud to every day for one year, that would provide exposure to 75,000 more words than if they had not been read to (Logan et al., 2019). 
Children should be encouraged and supported, by caregivers, in good reading behavior while they are very young. The caring style of parents affects the development of children, including language skills (Kleemans, Peeters, Segers, \& Verhoeven, 2012; Celik, 2020). Caregivers have a big role in being good reading models and giving an insight into reading to children (Wambiri \& Ndani, 2015; Niklas, Cohrssen, \& Tayler, 2016). The next study revealed that a good home learning environment and a good general environment were positively associated with children's numeracy abilities and supported language development (Niklas, Cohrssen, \& Tayler, 2016; Celik, 2020).

Thailand has densely populated areas or slums in big cities, such as Bangkok. Many rural people come to live in these areas of the cities when they need to find work. This benefits Thailand's economy. However, it means that people in these areas are of low socio-economic status, basic amenities are of poor quality and there is a lack of adequate living space; all of which can lead to extremely poor health (Strategic division and Housing Information, 2017). So, facilities should be organized to support both children and families in order to assist development of children in these areas. Reading is essential in engaging children with new ideas, new words, and a new world as they are growing up and have good health. This research aimed to study reading behavior promotion and the factors associated with promotion of reading behavior in early childhood in a densely populated area of metropolitan Bangkok.

\section{Method}

This cross-sectional study consisted of 635 families with young children, aged 3-6 years old. It was carried out at the four branches of Klong Toey Early Childhood Center, in metropolitan Bangkok. The sample size was estimated using the formula of Daniel (2005) and 228 participants were considered necessary.

\subsection{Research Instrument}

The research instrument was divided into three parts.

\section{1) Sociodemographic Variables}

This consisted of 12 items with multiple choice and open-ended questions. The researchers developed this tool based on literature reviews. They included age, gender and birth order of children, number of children in a family, education, and household income.

\section{2) Reading behavior promotion}

This part was divided into 3 sub-parts with a total of 19 items. Part 1 (6 items) the activities of the family and children, Part 2 (5 items) the reading promotion model, and Part 3 (8 items) the reinforcing factors. Participants identified their choices on a 5-point scale from "never" ( 1 point) to "regularly" (5 points) total scores could range from 19 to 95 . Cronbach's coefficient alpha was .86 .

3) Community environment and learning sources

We developed community environment and learning sources based on literature reviews and it consisted of 10 items. Participants identified their choices on a 5-point scale from "never agree" (1 point) to "agree" (5 points) total scores could range from 10 to 50. Cronbach's coefficient alpha was .72.

The data analysis consisted of two parts, descriptive and correlations. The descriptive analysis reported by the frequency and percentage distribution of the variables, while with correlations the Chi-square test was applied to examine the potential influence of independent variables on reading behavior promotion. The significance level for the analysis was set at $\mathrm{p}$-value $\leq 0.05$. This research study was approved by the IRB of Mahidol University, Bangkok.

\section{Results}

\subsection{Demographic Characteristics}

There were both male and female children (53.5\% and $46.5 \%$, respectively), 4,5 and 6 years old $(31.6 \%, 27.6 \%$, and $20.2 \%$ respectively). Most of them were the first child or the second child of the family $(61.0 \%$ and $27.6 \%$, respectively). The caregivers were mothers and fathers (54.8\% and $25.4 \%$, respectively), were $30-39$ years old $(41.2 \%)$ and had senior secondary education or vocational education $(29.4 \%)$, or had junior secondary education (26.3\%). Most of the families were nuclear families or extended families (54.4\% and $45.6 \%$, respectively). They took care of one child or two children (46.5\% and 38.6\% respectively). Most families spent less than 15 minutes per day doing activities with their children (43.5\%), some spent 15-30 minutes per day (36.8\%) while only a few spent more than 45 minutes per day $(6.5 \%)$. 


\subsection{Reading Behavior Promotion}

1) The activities of the family and children

Most families read books or fairy tales to their children a maximum of 5 times per month (40.4\%). During the past two months, caregivers read only fairy tales to their children while some never did ( $33.3 \%$ each). Some caregivers brought their children to the public library or a book shop 1-2 times a month while some never did (33.3\% each). Besides this, caregivers regularly paid attention to or gave praise to their children while they were reading $(44.7 \%)$ while some never praised or gave a gift to their reading children $(3.1 \%)$.

2) The reading promotion model

Some caregivers supported and encouraged their children when they bought books (27.6\%). Most caregivers did not read books to their children too fast or with an unclear rhythm (59.6\%). Some caregivers used the books they were reading for problem solving in the presence of theirchildren $(31.1 \%)$.

3) Reinforcing Factors

Most caregivers regularly praised their children when they were reading books or were interested in any book (46.1\%); some smiled and hugged their children when they were reading books or were interested in any book (44.7\%). Most caregivers did not listen to the story read by their children with boredom (53.1\%). In addition, some caregivers regularly gave a gift such as a book or stationery to their children (37.7\%).

\subsection{Community Environment Characteristics}

There were book shops or public libraries available in the community (39.5\%), or there were only a few kinds of books in the public library, so they did not want to bring their children to such a library (16.2\%); whereas some were uncertain that there were sufficient books in the public library for children $(45.8 \%)$. The community had reading activities $(30.3 \%)$; there was regular reading training provided for children in the community (17.1\%), and the community school regularly informed the caregivers of the reading promotions (16.7\%). However, some caregivers did not know that reading promotion activities were being organized in the community (22.4\%).

\subsection{Association Between Factors and Reading Behavior Promotion of Early Childhood Caregivers}

The findings were that the age of young children had a significant association with reading behavior promotion $(p=0.018)$. The research showed that for caregivers of 4-year-old children the incidence of a poor level of reading behavior promotion was significantly greater, at 4.7 times, than that of caregivers of three-year-old children ( $\mathrm{p}=0.007)$ (Table 1).

Table 1. Association between childhood characteristics factors and reading behavior promotion

\begin{tabular}{|c|c|c|c|c|c|c|}
\hline \multirow[b]{2}{*}{ Characteristics } & \multicolumn{2}{|c|}{ Reading behavior promotion } & \multirow{2}{*}{$\chi^{2}$} & \multirow{2}{*}{ df. } & \multirow{2}{*}{ OR. (95\% Confidence Interval) } & \multirow{2}{*}{ p-value } \\
\hline & Poor Level & Good Level & & & & \\
\hline Age & & & 0.0812 & 2 & & $0.018^{*}$ \\
\hline 3 years old** & $35(74.5)$ & $12(25.5)$ & & & 1.0 & \\
\hline 4 & $68(93.2)$ & $5(6.8)$ & & & $4.7(1.5-14.3)$ & $0.007 *$ \\
\hline $5-6$ & $92(85.2)$ & $16(14.8)$ & & & $2.0(0.8-4.6)$ & 0.115 \\
\hline Sex & & & 3.0765 & 1 & & 0.079 \\
\hline Female** & $86(81.1)$ & $20(18.9)$ & & & 1.0 & \\
\hline Male & $109(89.3)$ & $13(10.7)$ & & & $1.9(0.9-4.1)$ & 0.082 \\
\hline Number of births & & & 1.1734 & 2 & & 0.556 \\
\hline $1 * *$ & $117(84.2)$ & $22(15.8)$ & & & 1.0 & \\
\hline 2 & $54(85.7)$ & $9(14.3)$ & & & $1.1(0.5-2.6)$ & 0.778 \\
\hline$\geq 3$ & $24(92.3)$ & $2(7.7)$ & & & $2.3(0.5-10.2)$ & 0.292 \\
\hline
\end{tabular}

$* \mathrm{p}<0.05, \quad \chi^{2}=$ Chi-square, $\mathrm{OR}=$ Odds ratio, $\mathrm{CI}=$ Confidence interval

** Reference group

Educational level of caregivers also had a significant association with reading behavior promotion $(p=0.018)$. For caregivers who had primary education only, the incidence of a poor level of reading behavior promotion was significantly greater, at 5.4 times, than that of those educated to bachelor's level $(p=0.013)$ (Table 2). 
Family income had a significant association with reading behavior promotion $(\mathrm{p}=0.013)$. Caregivers who did not have enough income but were without loans had an incidence of a poor level of reading behavior promotion significantly greater, at 4.4 times, than that of caregivers who had enough income with savings $(\mathrm{p}=0.027)$ (Table 2). Caregivers who did not have enough income and also had loans had an incidence of a poor level of reading behavior promotion significantly greater, at 6.8 times, than that of caregivers who had enough income with savings $(\mathrm{p}=0.015)($ Table 2$)$.

Perception of the community environment of caregivers had a significant association with reading behavior promotion $(p=0.022)$. Caregivers who had a low level of community environment had an incidence of a poor of level of reading behavior promotion significantly greater, at 3.4 times, than that of caregivers who had a high level of community environment $(\mathrm{p}=0.028)$ (Table 4$)$.

Table 2. Association between family characteristics factors and reading behavior promotion

\begin{tabular}{ccccccc}
\hline \multirow{2}{*}{ Characteristics } & \multicolumn{2}{c}{ Reading behavior promotion } & \multirow{2}{*}{$\chi^{2}$} & df. & $\begin{array}{c}\text { OR. (95\% } \\
\text { Confidence Interval) }\end{array}$ & p-value \\
\cline { 2 - 4 } & Poor Level & Good Level & & & & 0.219 \\
Age (Year) & $43(79.6)$ & $11(20.4)$ & & & 1.0 & \\
$20-29 * *$ & $124(86.1)$ & $20(13.9)$ & & & $1.6(0.7-3.6)$ & 0.266 \\
$30-49$ & $28(93.3)$ & $2(6.7)$ & & & $3.6(0.7-17.4)$ & 0.114 \\
$50-69$ & & & 8.0218 & 2 & & $0.018^{*}$ \\
Educational Level & $38(74.5)$ & $13(25.5)$ & & & $2.2(1.0-5.0)$ & 0.055 \\
Bachelor** & $110(86.6)$ & $17(13.4)$ & & & $5.4(1.4-20.2)$ & $0.013^{*}$ \\
Secondary & $47(94.0)$ & $3(6.0)$ & & & & $0.013^{*}$ \\
Primary & & & 10.8292 & 3 & 1.0 & \\
Income & $43(74.1)$ & $15(28.9)$ & & & $2.0(0.9-4.6)$ & 0.099 \\
Enough with saving** & $75(85.2)$ & $13(14.8)$ & & & $4.4(1.2-16.4)$ & $0.027^{*}$ \\
Enough without saving & $38(92.7)$ & $3(7.3)$ & & & $6.8(1.5-31.7)$ & $0.015^{*}$ \\
Not enough but without loans & $39(95.1)$ & $2(4.9)$ & & & &
\end{tabular}

$* \mathrm{p}<0.05, \quad \chi^{2}=$ Chi-square, $\mathrm{OR}=$ Odds ratio, $\mathrm{CI}=$ Confidence interval

** Reference group

Table 3. Association between demographic of family factors and reading behavior promotion

\begin{tabular}{ccccccc}
\hline $\begin{array}{c}\text { Demographic of } \\
\text { family }\end{array}$ & \multicolumn{2}{c}{ Reading behavior promotion } & \multirow{2}{*}{$\chi^{2}$} & df. & $\begin{array}{c}\text { OR. (95\% } \\
\text { Confidence Interval) }\end{array}$ & p-value \\
\cline { 2 - 3 } & Poor Level & Good Level & & & & 0.691 \\
Family Type & & & 0.1576 & 1 & 1.0 & \\
Nuclear family** & $105(84.7)$ & $19(15.3)$ & & & $1.2(0.6-2.5)$ & 0.691 \\
Extended family & $90(86.5)$ & $14(13.5)$ & & & 1.5 \\
\hline
\end{tabular}

** Reference group

Table 4. Association between community environment factors and reading behavior promotion

\begin{tabular}{ccccccc}
\hline \multirow{2}{*}{$\begin{array}{c}\text { Demographic of community } \\
\text { environment }\end{array}$} & \multicolumn{2}{c}{$\begin{array}{c}\text { Reading behavior } \\
\text { promotion }\end{array}$} & & & $\begin{array}{c}\text { OR. (95\% } \\
\text { Confidence } \\
\text { Interval) }\end{array}$ & p-value \\
\cline { 2 - 3 } & Poor Level & Good Level & & df. & & $0.022^{*}$ \\
\hline Community environment & $133(82.1)$ & $29(17.9)$ & & & 1.0 & \\
High level** & $62(93.9)$ & $4(6.1)$ & & & $3.4(1.1-10.0)$ & $0.028^{*}$ \\
Low level & & & & & &
\end{tabular}

** Reference group 


\section{Discussion}

The results of the analysis showed that the following association factors were statistically significant $(\mathrm{p}<0.05)$; age of children (4 years old) (Table 1); education of caregivers (primary) (Table 2); family income (not enough but without loans or not enough and with loans) (Table 2), and the community environment (Table 4). However, the factors of sex and number of children, age of caregivers, and family type were not statistically significant.

In terms of children's age, language experience in the first three years of life is critical, and differences in children's ability to segment conversational speech signals are predictors of language development (Niklas, Cohrssen, \& Tayler, 2016). For young children, 2-3-year-olds, a good way is to set times for reading; such as after lunch or at bedtime and the family should make time for reading for pleasure. Reading for pleasure is not only important but it also improves reading test results as children grow up (Department for Education, 2015). Additionally, 34-year-olds are rapidly expanding their language, this can lead to being able to use many words, and an interest in learning to read (Armbruster, Lehr, \& Osborn, 2006). So, families should be supported with reading as it provides a context for joint engagement and serves as a conduit for language and cognitive development (Logan et al., 2019).

In terms of education and family income, research shows that children of families with higher socioeconomic status are faster at comprehending words and know $60 \%$ more words, than their lower income peers. Families in the lowerand middle-income groups are different due to lack of equal economic and educational opportunities for their children (Han \& Jun, 2013; Hindman, Wasik, \& Snell, 2016; Niklas, Cohrssen, \& Tayler, 2016).

Lastly, regarding the community environment; research has found that the home environment is associated with children's reading abilities, having more or fewer books to read, and opportunities for children to go to the library. Also, activities organized in children's libraries are effective at improving children's reading habits too (Niklas, Cohrssen, \& Tayler, 2016; Celik, 2020). This study encountered several limitations. First, the study employed a small sample size; thus, our results may not be generalizable to the entire child and family population. Future studies may be conducted in densely populated communities in other cities or regions so that a comparison and overall conclusion can be made and analyzed for planning. Second, we assessed socioeconomic data, reading behavior promotion, and community environment with only a self-reported questionnaire.

Based on the findings of the study; the recommendation is that a network or organization should be set up and organized within community environments, supporting convenience, proximity, and opportunity for local families to access information on reading.

\section{Acknowledgments}

This article was supported by the Thai Families Study Association. Authors would like to thank the participants for their valuable data.

\section{References}

Armbruster, B. B., Lehr, F., \& Osborn, J. (2006). A Child Becomes a Reader Proven Ideas from Research for Parents: Birth through Preschool (3rd ed.). The National Institute for Literacy, New Hampshire.

Ceka, A., \& Murati, R. (2016). The Role of Parents in the Education of Children. Journal of Education and Practice, 7(5), 61-64. Retrieved from https://files.eric.ed.gov/fulltext/EJ1092391.pdf

Celik, B. (2020). A Study on the Factors Affecting Reading and Reading Habits of Preschool Children. International Journal of English Linguistics, 10(1), 101-114. https://doi.org/10.5539/ijel.v10n1p101

Chettri, K., \& Rout, S. K. (2013). Reading habits- an overview. IOSR Journal of Humanities and Social Science, 14(6), 13-17. https://doi.org/10.9790/0837-01461317

Daniel, W. W. (2005). Biostatistics: A foundation for analysis in the health sciences (8th ed.). New York: John Wiley.

Department for Education, Government Organization. (2015). Reading: The next steps: Supporting higher standards in schools. London. 1-26. Retrieved from https://assets.publishing.service.gov.uk/government/ uploads/system/uploads/attachment_data/file/409409/Reading_the_next_steps.pdf

Hindman, A. H., Wasik, B. A., \& Snell, E. K. (2016). Closing the 30 Million Word Gap: Next Steps in Designing Research to Inform Practice. Child Development Perspectives, 10(2), 1-6. https://doi.org/10.1111/cdep.12177

Kleemans, T., Peeters, M., Segers, E., \& Verhoeven, L. (2012). Child and home predictors of early numeracy 
skills in kindergarten. Early Childhood Research Quarterly, 27(3), 471-477. https://doi.org/10.1016/j.ecresq.2011.12.004

Kourkouta, L., Iliadis, C., Frantzana, A., \& Vakalopoulou, V. (2018). Reading and Health Benefits. Journal of Healthcare Communications, $\quad 3(4), \quad$ Retrieved from https://www.researchgate.net/publication/329601541_Reading_and_Health_Benefits

Levine, L. E., \& Munsch. J. A. (2018). Child Development: An Active Learning Approach (3rd ed.). SAGE Publications, Inc., California.

Logan, A. R. J., Justice, L. M., Melike, Y., \& Chaparro-Moreno, L. J. (2019). When Children Are Not Read to at Home: The Million Word Gap. Journal of Developmental \& Behavioral Pediatrics, 40(5), $383-386$. https://doi.org/10.1097/DBP.0000000000000657

National Statistics Office (NSO), Ministry of Digital Economic and Society. (2020). The 2018 Reading of Population Survey. Thailand: Statistical Forecasting Division, National Statistical Office. Bangkok.

Niklas, F., Cohrssen, C., \& Tayler, C. (2016). The Sooner, the Better: Early Reading to Children. SAGE Open, October-December, 1-11. https://doi.org/10.1177/2158244016672715

Strategic division and Housing Information. (2017). Data of low-income Community. National Housing Authority, Bangkok.

The NSW Office of Child Care. (2006). A basic introduction to child development theories. New South Wales, Australia: Centre for Learning Innovation, Department of Education and Training.

UNESCO Institute for Statistics. (2017). More Than One-Half of Children and Adolescents Are Not Learning World Wide. Fact sheet No 46. September. 1-25. Retrieved from http://uis.unesco.org/sites/default/files/documents/fs46-more-than-half-children-not-learning-en-2017.pdf

Wambiri, G. N., \& Ndani, M. N. (2015). Relative Contributions of Caregivers' Level of Education, Role Definition and Average Household Income to caregiver Involvement in Children's Emergent Reading. Journal of Education and Practice, 6(24), 108-115.

Yeon, S. H., \& Woo, P. J. (2013). Parental Involvement in Child's Development: Father vs. Mother. Open Journal of Medical Psychology, 2, 1-6. https://doi.org/10.4236/ojmp.2013.24B001

\section{Copyrights}

Copyright for this article is retained by the author(s), with first publication rights granted to the journal.

This is an open-access article distributed under the terms and conditions of the Creative Commons Attribution license (http://creativecommons.org/licenses/by/4.0/). 